\title{
Mg acceptor level in InN epilayers probed by photoluminescence
}

\author{
N. Khan, N. Nepal, A. Sedhain, J. Y. Lin, and H. X. Jiang ${ }^{a)}$ \\ Department of Physics, Kansas State University, Manhattan, Kansas 66506-2601
}

(Received 6 April 2007; accepted 7 June 2007; published online 2 July 2007)

\begin{abstract}
Mg-doped InN epilayers were grown on sapphire substrates by metal organic chemical vapor deposition. Effects of $\mathrm{Mg}$ concentration on the photoluminescence (PL) emission properties have been investigated. An emission line at $\sim 0.76 \mathrm{eV}$, which was absent in undoped InN epilayers and was about $60 \mathrm{meV}$ below the band-to-band emission peak at $\sim 0.82 \mathrm{eV}$, was observed to be the dominant emission in Mg-doped InN epilayers. The PL spectral peak position and the temperature dependent emission intensity corroborated each other and suggested that the $\mathrm{Mg}$ acceptor level in $\mathrm{InN}$ is about $60 \mathrm{meV}$ above the valance band maximum. (c) 2007 American Institute of Physics. [DOI: $10.1063 / 1.2753537$ ]
\end{abstract}

In recent years, research interest in indium nitride $(\mathrm{InN})$ has significantly increased due to the confirmation of its small band gap energy of $\sim 0.62-0.7 \mathrm{eV}$ (Refs. 1-9) and its potential applications in semiconductor devices, such as light emitting diodes, laser diodes, high efficiency solar cells, and high performance electronic devices, and in the telecommunications wavelength region $(1.55 \mu \mathrm{m}) .^{10-12}$ Achieving $p$-type conduction in $\mathrm{InN}$ and high In content InGaN alloys is essential for many device applications but has been exceedingly difficult due to the fact that as-grown InN epilayers are generally highly $n$ type. There has been strong evidence that InN contains an electron accumulation layer on its surface. ${ }^{4}$ Thus even if $p$-type conductivity in bulk $\mathrm{InN}$ is achieved by $\mathrm{Mg}$ doping, its surface will remain highly $n$ type which creates difficulties in the demonstration of $p$-type $\mathrm{InN}$, as electrical measurements are often dominated by surface n-type conducting layers. ${ }^{13,14}$

Compared to $\mathrm{Mg}$-doped $\mathrm{GaN}$, very few studies have been done so far concerning the basic properties of $\mathrm{Mg}$ doped InN. ${ }^{15-18}$ A previous study using X-ray absorption fine structure analysis suggested that $\mathrm{Mg}$ atoms occupy either the In metal $\left(\mathrm{Mg}_{\text {In }}\right)$ or the interstitial $\left(\mathrm{Mg}_{\text {Int }}\right)$ site; Hall effect measurements, however, revealed a $n$-type behavior. ${ }^{16}$ More recently, the evidence of a buried $p$-type layer in $\mathrm{Mg}$ doped InN was provided by capacitance-voltage $(C V)$ measurements. ${ }^{17}$ Further evidence of a buried $p$ layer beneath a surface electron accumulation layer in heavily $\mathrm{Mg}$-doped $\mathrm{InN}$ was provided by variable magnetic field Hall effect and $C V$ measurements, from which an energy level of about $110 \mathrm{meV}$ was suggested for the $\mathrm{Mg}$ acceptors in $\mathrm{InN}{ }^{18}$ So far, detailed studies concerning the optical transitions and the $\mathrm{Mg}$ acceptor energy level in Mg-doped $\mathrm{InN}$ have not been possible due to the fact that most $\mathrm{Mg}$-doped InN films exhibit no (or weak) photoluminescence (PL) emission.

In this letter, we report on the growth and PL emission characteristics of $\mathrm{Mg}$-doped $\mathrm{InN}$ epilayers grown on sapphire substrates by metal organic chemical vapor deposition (MOCVD). Effects of the $\mathrm{Mg}$ flow rate $\left(R_{\mathrm{Mg}}\right)$ on the PL emission properties of $\mathrm{Mg}$-doped $\mathrm{InN}$ epilayers have been investigated by varying $R_{\mathrm{Mg}}$ from 8.5 to $60 \mathrm{ml} / \mathrm{min}$, corresponding to $\mathrm{Mg}$ doping concentration of $1.8 \times 10^{20}-1.3 \times 10^{21} \mathrm{~cm}^{-3}$. The PL spectroscopy system

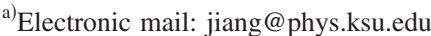

consists of a 100 fs Ti:sapphire laser $\left(\lambda_{\text {exc }}=780 \mathrm{~nm}\right)$, a $0.3 \mathrm{~m}$ monochromator, and an InGaAs detector. Electrical properties of Mg-doped InN epilayers were examined by Hall effect measurement. X-ray diffraction (XRD) was employed to study the crystalline quality of $\mathrm{Mg}$-doped $\mathrm{InN}$.

The $0.2 \mu \mathrm{m}$ thick $\mathrm{Mg}$-doped InN epilayers were grown by MOCVD on sapphire (0001) substrates with $1.5 \mu \mathrm{m}$ thick GaN epilayer templates. Trimethylindium, trimethylgallium, and $\mathrm{NH}_{3}$ were used as $\mathrm{In}, \mathrm{Ga}$, and $\mathrm{N}$ sources, respectively. For $\mathrm{Mg}$ doping, bis-cyclopentadienylmagnesium $\left(\mathrm{CP}_{2} \mathrm{Mg}\right)$ was transported into the growth chamber during InN growth. Atomic force microscopy revealed a root mean square (rms) of surface roughness of about $25-30 \mathrm{~nm}$ on a $10 \times 10 \mu \mathrm{m}^{2}$ area scan, which was comparable to that of undoped $\mathrm{InN}$. The surface morphology started to deteriorate when $R_{\mathrm{Mg}}$ exceeded $35 \mathrm{ml} / \mathrm{min}$. Both undoped and $\mathrm{Mg}$-doped InN films were shown to be single crystals based on XRD measurements with a $c$ spacing of around $0.568 \mathrm{~nm}$. The full width at half maximum (FWHM) of the rocking curve of the (0002) plane of undoped (Mg-doped) InN epilayers was 500-540 (550-630) arc sec. Hall effect measurement was attempted to measure the conductivity of $\mathrm{Mg}$-doped $\mathrm{InN}$ epilayers. Complete electron compensation by $\mathrm{Mg}$ acceptors could not be observed. Instead, increasing the $\mathrm{Mg}$ flow rate from 8.5 to $60 \mathrm{ml} / \mathrm{min}$ reduced the free electron concentration $(n)$ from $2 \times 10^{19}$ to $3 \times 10^{18} \mathrm{~cm}^{-3}$ and the $n$-type conductivity $(\sigma)$ from 1250 to $125(\Omega \mathrm{cm})^{-1}$ upon postgrowth thermal annealing at $500{ }^{\circ} \mathrm{C}$ for $4 \mathrm{~min}$. However, due to the presence of the surface electron accumulation layer, the effects of postgrowth thermal annealing process in $\mathrm{Mg}$ doped $\mathrm{InN}$ epilayers seem rather complicated and remain to be understood. Furthermore, the postgrowth thermal annealing process may also alter the profile of the surface electron accumulation layer. In order to avoid the complications caused by the postgrowth thermal annealing process in data analysis, we have carried out systematic comparison studies only for unannealed samples, which were shown by the Hall effect measurement to have a comparable free electron concentration.

Figure 1 shows $10 \mathrm{~K} \mathrm{PL}$ spectra of a set of Mg-doped InN grown under different $R_{\mathrm{Mg}}$ where the PL spectrum of an undoped InN epilayer is also included for comparison. The dominant PL emission peak is at $0.82 \mathrm{eV}$ in the undoped $\mathrm{InN}$ epilayers, which is higher than the recently reported band gap of InN $(0.62-0.7 \mathrm{eV}) .^{1-9}$ This spectral blueshift has 


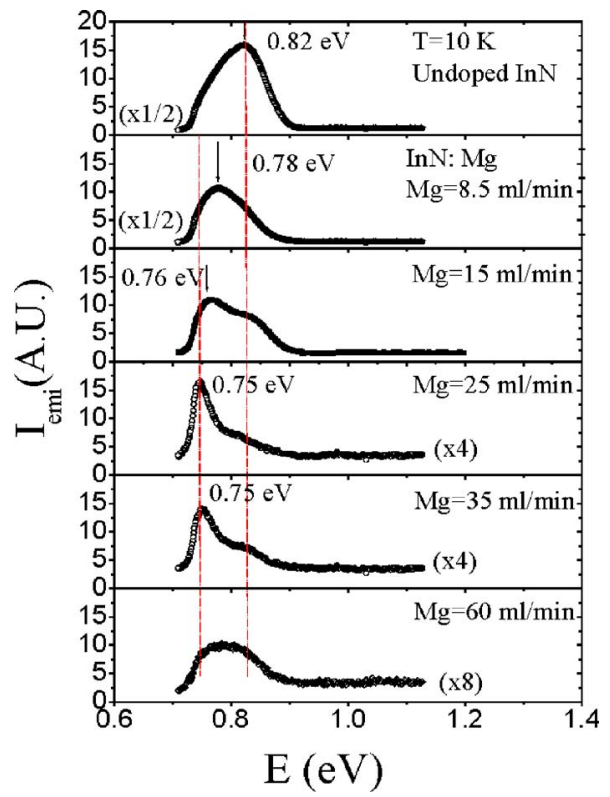

FIG. 1. $10 \mathrm{~K}$ PL spectra of Mg doped InN epilayers grown under different Mg flow rates $\left(R_{\mathrm{Mg}}\right)$. PL spectrum of an undoped $\mathrm{InN}$ epilayer is also included for comparison. All samples are unannealed.

been previously observed in both optical absorption ${ }^{19,20}$ and PL spectra of InN (Refs. 20-22) and can be accounted for by the fact that the electron Fermi level $\left(E_{F}\right)$ is above the conduction band minimum or the so-called Moss-Burstein blueshift, which was observed to increase with an increase of the free electron concentration. ${ }^{19-22}$ With respect to the conduction band minimum, $E_{F}$ can be written as $E_{F}=\hbar^{2} / 2 m^{*}$ $\left(3 \pi^{2} n / v_{D}\right)^{2 / 3},{ }^{23}$ where $v_{D}$ is the degeneracy factor which is 2 for this case, and $n$ and $m^{*}$ are the electron concentration and electron effective mass, respectively. Using $m^{*} \sim 0.11 m_{0}$ (Ref. 24) and $n=(1.9-2.0) \times 10^{19} \mathrm{~cm}^{-3}$ for undoped $\mathrm{InN}$, we obtained $E_{F}=140-150 \mathrm{meV}$. Based on this and the room temperature spectral peak position of about $0.80 \mathrm{eV}$ observed in the undoped $\mathrm{InN}$, the band gap of $\mathrm{InN}$ is thus deduced to be $0.66-0.65 \mathrm{eV}$ which is in reasonable agreement with the previously reported band gap of $\mathrm{InN}$ $(\sim 0.62-0.7 \mathrm{eV})$. We thus label the $0.82 \mathrm{eV}$ emission line as the band-to-band emission line in $\mathrm{InN}$.

Compared to the undoped InN layer, an additional emission line at $\sim 0.76 \mathrm{eV}$ emerges and is the dominant emission line in $\mathrm{Mg}$-doped $\mathrm{InN}$ epilayers. Since this $0.76 \mathrm{eV}$ emission line is absent in undoped $\mathrm{InN}$, we attribute it to the $\mathrm{Mg}$ related line. This Mg-related emission line is about $60 \mathrm{meV}$ below the band edge emission line at $0.82 \mathrm{eV}$. Figure 2 summarizes the influence of $R_{\mathrm{Mg}}$ on the PL emission properties of the Mg-related line in terms of (a) the spectral peak position $E_{p}$, (b) linewidth FWHM, and (c) the intensity ratio of the Mg-related emission line to the band edge emission line. Both $E_{p}$ and FWHM initially decrease with increasing $R_{\mathrm{Mg}}$ up to $25 \mathrm{ml} / \mathrm{min}$ and then increase. A similar trend is seen for the band-to-band emission line at $0.82 \mathrm{eV}$. The spectral blueshift seen for $R_{\mathrm{Mg}}>25 \mathrm{ml} / \mathrm{min}$ could be due to an increase in the incorporation of defects and impurities at higher $R_{\mathrm{Mg}}$ that increase $n$ and $E_{F}{ }^{25}$ The integrated emission intensity $\left(I_{\mathrm{emi}}\right)$ of the Mg-related transition is observed to decrease exponentially with increasing $\mathrm{Mg}$ doping concentration, following a similar trend as the $\mathrm{Mg}$-related transition line in Mg-doped GaN. ${ }^{26}$ However, the relative intensity of the $\mathrm{Mg}$ -

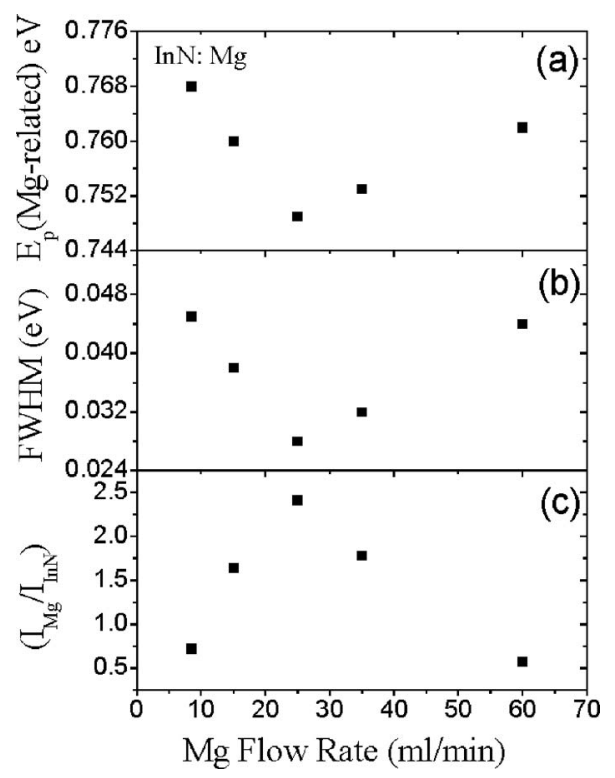

FIG. 2. Variations of the (a) spectral peak position $E_{p}$, (b) full width at half maximum (FWHM), and (c) intensity ratio of the $\mathrm{Mg}$-related emission line to the band-to-band transition line with the $\mathrm{Mg}$ flow rate $R_{\mathrm{Mg}}$. All samples are unannealed.

related emission line to the band-to-band emission line exhibits a maximum at $R_{\mathrm{Mg}}=25 \mathrm{ml} / \mathrm{min}$, as shown in Fig. 2(c).

Figure 3 presents the PL spectra measured at different temperatures for the $\mathrm{Mg}$-doped $\mathrm{InN}$ epilayer grown under $R_{\mathrm{Mg}}=15 \mathrm{ml} / \mathrm{min}$. The spectral peak separation of about $60 \mathrm{meV}$ between the Mg-related and band-to-band emission lines is clearly measured at $T<100 \mathrm{~K}$. At $T>100 \mathrm{~K}$, only the Mg-related emission line can be resolved. Both emission lines exhibit a blueshift with increasing temperature. This blueshift with temperature is in a sharp contrast to the temperature dependence of the direct band gap $\left(E_{g}\right)$ in most semiconductors, in which a reduction of $E_{g}$ with increasing

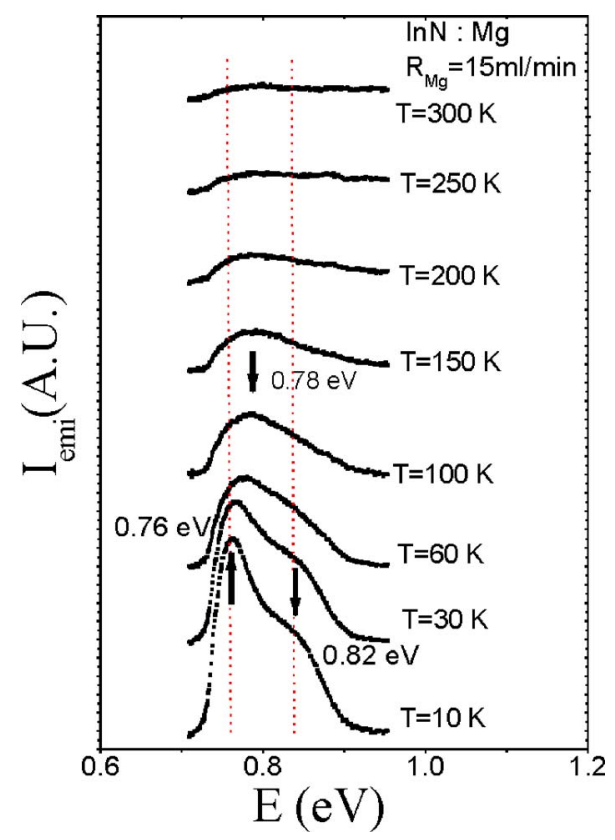

FIG. 3. PL spectra of $\mathrm{Mg}$ doped $\mathrm{InN}$ grown under the $\mathrm{Mg}$ flow rate $R_{\mathrm{Mg}}=15 \mathrm{ml} / \mathrm{min}$, measured at different temperatures. All samples are unannealed.

Downloaded 12 Jul 2010 to 129.118.86.45. Redistribution subject to AlP license or copyright; see http://apl.aip.org/apl/copyright.jsp 


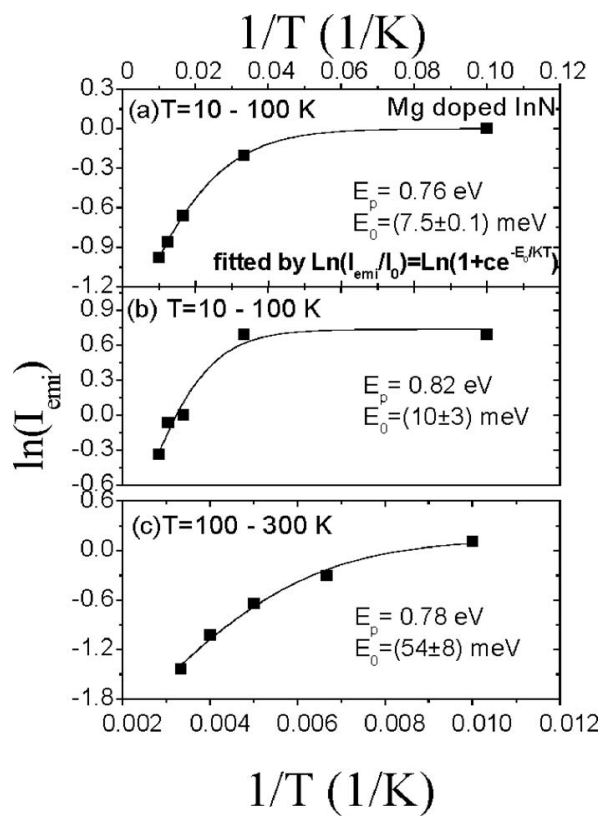

FIG. 4. The Arrhenius plots of the PL emission intensity, $\ln \left(I_{\text {emi }}\right)$ vs $1 / T$, for (a) the Mg-related emission line measured in the temperature range of $T=10-100 \mathrm{~K}$, (b) the band edge emission line measured in the temperature range of $T=10-100 \mathrm{~K}$, and (c) the Mg-related emission line measured at $T=100-300 \mathrm{~K}$. The fitted activation energies $\left(E_{0}\right)$ are indicated in the figure. All samples are unannealed.

temperature is typically observed. The spectral blueshift with temperature may be caused by the electron Fermi level increase due to the free electron concentration increase at higher temperatures. ${ }^{1,27}$ This interpretation is also supported by the Hall effect measurement result that revealed a linear increase of the electron concentration with temperature.

The Arrhenius plots of PL emission intensities $\left(I_{\mathrm{emi}}\right)$ measured in different temperature ranges for Mg-doped InN with $R_{\mathrm{Mg}}=15 \mathrm{ml} / \mathrm{min}$ are shown in Fig. 4. The solid lines are the least squares fit of the data with equation $I_{\text {emi }}$ $(T)=I_{0} /\left[1+C \exp \left(-E_{0} / K T\right)\right]$, where $E_{0}$ is the activation energy of $I_{\mathrm{emi}}$. The Arrhenius plots in the temperature range of $10-100 \mathrm{~K}$, as shown in Figs. 4(a) and 4(b), yield activation energies of 7.5 and $10 \mathrm{meV}$, respectively, for the $\mathrm{Mg}$-related emission line and the band-to-band emission line, which may be accounted for by the existence of nonradiative recombination channels. ${ }^{12,21}$ In the temperature range of $100-300 \mathrm{~K}$, the activation process is governed by an activation energy of $54 \mathrm{meV}$. This activation energy coincides fairly well with the spectral peak energy difference of about $60 \mathrm{meV}$ between the Mg-related and the band-to-band transition lines. We therefore believe that the $\mathrm{Mg}$ acceptor energy level in $\mathrm{InN}$ is about $60 \mathrm{meV}$ above the valance band maximum. The $\mathrm{Mg}$ acceptor binding energy of $60 \mathrm{meV}$ in $\mathrm{InN}$ obtained from our present work matches well with a recently reported value of about $62 \mathrm{meV}$ observed in $\mathrm{Mg}$-doped InN epilayers grown by molecular beam epitaxy. ${ }^{28}$

In summary, we have grown by MOCVD and studied the PL emission characteristics of Mg-doped InN epilayers. An emission line of about $60 \mathrm{meV}$ below the band-to-band emission, which was absent in undoped InN epilayers, was ob- served in Mg-doped InN. Together with the temperature dependent PL emission intensity result, we suggest that the $\mathrm{Mg}$ acceptor level in $\mathrm{InN}$ is about $60 \mathrm{meV}$ above the valance band maximum.

This work was supported by NSF (DMR-0504610) and AFOSR (FA9550-06-1-0441).

${ }^{1}$ J. Wu, W. Walukiewicz, K. M. Yu, J. W. Ager, III, E. E. Haller, H. Lu, W. J. Schaff, Y. Saito, and Y. Nanishi, Appl. Phys. Lett. 80, 3967 (2002).

${ }^{2}$ J. Wu, W. Walukiewicz, K. M. Yu, W. Shan, J. W. Ager, III, E. E. Haller, Hai Lu, W. J. Schaff, W. K. Metzger, and Sarah Kurtz, J. Appl. Phys. 94, 6477 (2003).

${ }^{3}$ S. H. Wei, X. Nie, I. G. Batyrev, and S. B. Zhang, Phys. Rev. B 67, 165209 (2003).

${ }^{4}$ I. Mahboob, T. D. Veal, C. F. McConville, H. Lu, and W. J. Schaff, Phys. Rev. Lett. 92, 036804 (2004).

${ }^{5}$ W. Walukiewicz, Physica E (Amsterdam) 20, 300 (2004).

${ }^{6}$ S. X. Li, K. M. Yu, J. Wu, R. E. Jones, W. Walukiewicz, J. W. Ager, III, W. Shan, E. E. Haller, Hai Lu, and William J. Schaff, Phys. Rev. B 71, 161201(R) (2005).

${ }^{7}$ P. Carrier and S. H. Wei, J. Appl. Phys. 97, 033707 (2005).

${ }^{8}$ S. P. Fu, T. T. Chen, and Y. F. Chen, Semicond. Sci. Technol. 21, 244 (2006).

${ }^{9}$ W. Walukiewicz, J. W. Ager, K. M. Yu, Z. Liliental-Weber, J. Wu, S. X. Li, R. E. Jones, and J. D. Delinger, J. Phys. D 39, R38 (2006).

${ }^{10}$ A. G. Bhuiyan, A. Hashimoto, and A. Yamamoto, J. Appl. Phys. 94, 2779 (2003).

${ }^{11}$ M. C. Johnson, S. L. Konsek, A. Zettl, and E. D. Bourret-Courchesne, J. Cryst. Growth 272, 400 (2004).

${ }^{12}$ R. Intartagilla, B. Maleyre, S. Ruffenach, O. Briot, T. Taliercio, and B. Gil, Appl. Phys. Lett. 86, 142104 (2005).

${ }^{13}$ V. Camilla, M. Niebelschutz, G. Ecke, V. Lebedev, O. Ambacher, M. Hmmerlich, S. Krischok, J. A. Schaefer, H. Lu, and W. J. Schaff, Phys. Status Solidi A 203, 59 (2006).

${ }^{14}$ V. Cimalla, M. Niebelschutz, G. Ecke, O. Ambacher, R. Goldhahn, H. Lu, and W. J. Schaff, Phys. Status Solidi C 3, 1721 (2006).

${ }^{15}$ V. V. Mamutin, V. A. Vekshin, V. Yu. Davydov, V. V. Ratnikov, Yu. A. Kudriavtsev, B. Ya. Ber, V. V. Emtsev, and S. V. Ivanov, Phys. Status Solidi A 176, 373 (1999).

${ }^{16}$ A. V. Blant, T. S. Cheng, N. J. Jeffs, L. B. Flannery, I. Harrison, J. F. W. Mosselmans, A. D. Smith, and C. T. Foxen, Mater. Sci. Eng., B 59, 218 (1999).

${ }^{17}$ R. E. Jones, K. M. Yu, S. X. Li, W. Walukiewicz, J. W. Ager, E. E. Haller, H. Lu, and W. J. Schaff, Phys. Rev. Lett. 96, 125505 (2006).

${ }^{18}$ P. A. Anderson, C. H. Swartz, D. Carder, R. J. Reeves, S. M. Durbin, S. Chandril, and T. H. Myers, Appl. Phys. Lett. 89, 184104 (2006).

${ }^{19}$ J. Wu, W. Walukiewicz, S. X. Li, R. Armitage, J. C. Ho, E. R. Weber, E. E. Haller, Hai Lu, William J. Schaff, A. Barcz, and R. Jakiela, Appl. Phys. Lett. 84, 2805 (2004).

${ }^{20}$ K. Sugita, H. Takatsuka, A. Hashimoto, and A. Yamamoto, Phys. Status Solidi B 240, 421 (2003).

${ }^{21}$ G. W. Shu, P. F. Wu, M. H. Lo, J. L. Shen, T. Y. Lin, H. J. Chang, Y. F. Chen, C. F. Shih, C. A. Chang, and N. C. Chen, Appl. Phys. Lett. 89, 131913 (2006).

${ }^{22}$ M. Higashiwaki, T. Inushima, and T. Matsui, Phys. Status Solidi 240, 417 (2003).

${ }^{23}$ K. W. Boer, Survey of Semiconductor Physics: Electrons and other Particles in Bulk Semiconductors (Van Nostrand Reinhold, New York, 1990), p. 240.

${ }^{24}$ S. P. Fu and Y. F. Chen, Appl. Phys. Lett. 85, 1523 (2004).

${ }^{25}$ S. X. Li, R. E. Jones, E. E. Haller, K. M. Yu, W. Walukiewicz, J. M. Ager, Z. L. Weber, H. Lu, and W. J. Schaff, Appl. Phys. Lett. 88, 151101 (2006).

${ }^{26}$ M. Lachab, D.-H. Youn, R. S. Qhalid Fareed, T. Wang, and S. Sakai, Solid-State Electron. 44, 1669 (2000).

${ }^{27}$ F. Chen, A. N. Cartwright, H. Lu, and W. J. Schaff, Physica E (Amsterdam) 20, 308 (2004).

${ }^{28}$ X. Wang, S. B. Che, Y. Ishitani, and A. Yoshikawa, Appl. Phys. Lett. 90, 201913 (2007). 